Andrews University

Digital Commons @ Andrews University

Honors Theses

Undergraduate Research

4-3-2019

\title{
The Effects of Adverse Childhood Experiences on Parenting Practices
}

Talisa C. Gonzalez

Andrews University, talisa@andrews.edu

Follow this and additional works at: https://digitalcommons.andrews.edu/honors

Part of the Family, Life Course, and Society Commons

\section{Recommended Citation}

Gonzalez, Talisa C., "The Effects of Adverse Childhood Experiences on Parenting Practices" (2019). Honors Theses. 207.

https://dx.doi.org/10.32597/honors/207

https://digitalcommons.andrews.edu/honors/207

This Honors Thesis is brought to you for free and open access by the Undergraduate Research at Digital Commons @ Andrews University. It has been accepted for inclusion in Honors Theses by an authorized administrator of Digital Commons @ Andrews University. For more information, please contact repository@andrews.edu. 


\section{J. N. Andrews Honors Program \\ Andrews University}

HONS 497

Honors Thesis

The Effects of Adverse Childhood Experiences on Parenting Practices

Talisa C. Gonzalez

April 3, 2019

Advisors: Dr. Harvey Burnett \& Dr. Karl Bailey

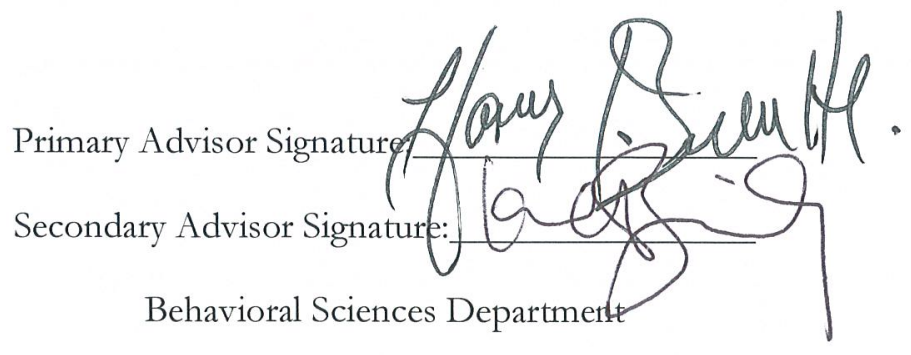




\begin{abstract}
Adverse childhood experiences (ACEs) refer to traumatic sources of stress that a child may endure before the age of 18 such as household dysfunction, neglect, various types of abuse (i.e., physical, verbal, sexual), parental separation, and witnessing violence. These kinds of traumatic experiences have been linked to poor mental, emotional, social, and physical health in adulthood. Researchers found associations between early childhood experiences of abuse and individuals' later abusive parenting of their own children. Although the effects of ACEs can have detrimental consequences, resilience-both internal and external-can mitigate these negative effects through the use of protective factors such as personal coping skills and social support. The study examined the predicting relationship between adverse childhood experiences and the quality of current parenting practices. In addition, it examined the role of resilience as a protective factor in this relationship. A nested hierarchical regression showed that ACEs were not a significant predictor of positive or negative parenting practices. Instead, resilience was a substantial direct predictor of positive parenting practices and parental stress was a substantial direct predictor of negative parenting practices. Furthermore, an interaction between ACEs and resilience found that individuals with a high ACE score and high resilience used corporal punishment than individuals with a high ACE score and low resilience. These results suggest an intergenerational trauma cycle in which childhood trauma is passed down through negative parenting practices. Researching ACEs within a framework that incorporates the parent-child relationship highlights the importance of decreasing parental stress and improving positive parenting to break this trauma cycle.
\end{abstract}

Keywords: adverse childhood experiences, developmental stress, parenting practices, resilience 


\section{Literature Review}

\section{Developmental Stress}

While the early years of life are often a time of significant growth, they are also a time of vulnerability. This characteristic of early childhood has inspired researchers to highlight the unique opportunity that early childhood has to lay the foundation for healthy development in the future (Cooper, Masi, \& Vick, 2009). Adversities experienced in early childhood disrupt normative brain development, structure, and functioning, potentially more than any other stage of childhood development (Enlow, Egeland, Blood, Wright, \& Wright, 2012; Pechtel \& Pizzagalli, 2011). These damaging neurological effects lead to behavioral, emotional, and cognitive deficits (Cooper et al., 2009; De Bellis, Woolley, \& Hooper, 2013; Landsford et al., 2002). For example, Middlebrooks and Audage (2008) found that formation of the hippocampus, an area imperative for memory formation and learning, is disrupted due to early adverse exposure. The neurological implications resulting from early exposure to adversities, as well as other consequences of extensive toxic stress caused by sustained adverse experiences, eventually lead to a decrease in a child's stress threshold. This makes the child even more susceptible to the negative effects of early traumatic experiences. Beyond emotional and cognitive impairments, a child's physical health can also be greatly impacted. Due to the high levels of stress hormones (cortisol) that are released when the body undergoes traumatic experiences, the body's immune response weakens, leaving the child more vulnerable to a variety of infections and chronic health issues (National Scientific Council on the Developing Child, 2005).

\section{Adverse Childhood Experiences (ACEs)}


The earliest examinations of adverse childhood experiences were conducted by a cohort of medical doctors at Kaiser Permanente's San Diego Health Appraisal Clinic (Felitti et al., 1998). It was this group of researchers who coined the well-known term "adverse childhood experiences", or ACEs. In this original ACEs study, the researchers noticed that the dropout rate for participants in a weight loss program was over $50 \%$, even though they were consistently losing weight. However, one common factor among many of the drop out participants was their experience of childhood sexual abuse. To further investigate this predicament, Felitti and his colleagues teamed up with the Center for Disease Control and Prevention to launch the Adverse Childhood Experiences Study. Their study focused on seven categories of childhood adversities: psychological, physical, and sexual abuse; violence against mother; living with household members who suffered from substance abuse, mental illnesses/suicidal thoughts or actions; or living with household members who had been imprisoned.

The ACEs study revealed groundbreaking discoveries. Despite what many people believed, ACEs were common. Over two thirds of their 17,000 participants had experienced at least one adverse childhood experience. The study also revealed that individuals rarely experienced only one adverse childhood experience. In fact, out of the 17,000 participants who had experienced at least one adverse childhood experience, $87 \%$ of them had experienced more than one. They also discovered that there was a direct link between childhood trauma and adultonset diseases. This included a higher risk for depression, alcoholism, physical inactivity, severe obesity, and poor self-reported overall health (Felitti et al., 1998). Finally, the results revealed that there was a graded dose-response relationship between the number of ACEs endured and the amount of risk for these various adult health issues: the more trauma experienced, the higher the 
risk for physical, social, behavioral, and mental problems in adulthood. Unfortunately, many of these health problems related to ACEs were found to be co-morbid, or co-occurring.

Since these earliest findings, subsequent researchers have invested in further defining ACEs and examining their effects. Although it is agreed upon that, by definition, ACEs occur before the age of 18 , there has been a variety of attempts to define the theoretical framework. Kalmakis and Chandler (2014) operationally define ACEs as childhood events varying in severity and often chronic that "occur in a child's family or social environment to cause harm or distress, thereby disrupting a child's physical or psychological health and development" (p. 1495). Over time, the original seven ACEs categories (Felitti et al., 1998) have expanded to also include physical neglect, emotional neglect, and losing a parent to separation or divorce (Anda et al., 2002; Resier, McMillian, Wright, \& Asmundson, 2014). Recent studies continue to support and strengthen the original claims made by Felitti and colleagues (1998) that the repercussions of ACEs can persist into adulthood. They demonstrate the association between ACEs and an increased risk for physical health problems (Chartier, Walker, \& Naimark, 2010); depressive disorders and adulthood anxiety (Chapman et al., 2004; Resier et al., 2014); and alcohol abuse (Anda et al., 2002; Kestila et al., 2008). ACEs have even been shown to increase the likelihood of females becoming victims of intimate partner violence and males becoming perpetrators of intimate partner violence (Whitfield, Anda, Dube, \& Felitti, 2003).

\section{Parenting Practices and Developmental Stress}

Research suggests that ACEs may extend beyond the individual and transmit across successive generations. Randell, O'Malley, and Dowd (2015) found that the number of ACEs experienced by parents are positively correlated with the number of ACEs that their children 
experience. Another study revealed that environmental stress within female rodents can alter maternal care by decreasing licking and grooming, a sign of positive nurturing behavior (Champagne \& Meaney, 2001; Champagne \& Meaney, 2006). Although this research was not directly conducted on human subjects, it builds on the notion that parent-child interactions are vulnerable to developmental stress experienced by the parents themselves and that environmental adversity, such as ACEs, can be transmitted across generations.

There is additional reason to believe that ACEs may be transmitted across generations through the use of negative parenting practices. Research has revealed the intergenerational continuity of parenting which occurs when an earlier generation purposefully or unintentionally influences the parenting attitudes and behavior of the next generation (Van Ijzendoorn, 1992). This relationship was demonstrated by observing that current parents use very similar parenting styles and strategies that they themselves experienced during their own childhood (Putallaz, Costanzo, Grimes, \& Sherman, 1998). For example, Belsky (1984) discovered that there was an association between early experiences of child abuse and individuals' later abusive parenting of their own children. These findings indicate that parenting practices may be passed down, leading to a continuation of ACEs throughout multiple generations.

\section{Resilience and Protective Factors}

Despite the negative effects of childhood trauma on both the individuals who directly experience them and potentially the offspring of those individuals, resilience plays an imperative role in mitigating these effects (Burnett \& Wahl, 2015). Resilience is defined as an individual's ability to cope with adversity (Everly, Welzant, \& Jacobson, 2008; Wagnild \& Young, 1993). Various studies have shown that social and emotional support, especially in the form of a single 
trusted adult in childhood, can build resilience which substantially mitigates many of the harmful consequences of ACEs (Bellis, Hardcastle, Ford, Hughes, \& Ashton, 2017; Logan-Greene, Green, Nurius, \& Longhi, 2013). Other protective factors were positive personal coping skills (Poole, Dobson, \& Pusch, 2017); resilience building interventions like yoga and meditation (Whitaker et al., 2014); attending a safe school (Hawkins, Kosterman, Catalano, Hill, \& Abbott, 2005); residing in a safe neighborhood (Moore \& Ramirez, 2016); and trauma-focused cognitivebehavioral therapy (Soleimanpour, Geierstanger, \& Brindis, 2017; Wethington et al., 2008).

\section{Current Study}

The current study examined the predictive relationship between subjects' adverse childhood experiences and the quality of subjects' current parenting practices among a national population. In addition, the study also examined the protective role that resilience plays in moderating this relationship. Specifically, this study examined the following hypothesis:

1. A moderate direct predicting relationship between the total number of ACEs and negative parenting practices will exist.

2. Resilience will act as a moderator in this relationship_-higher levels of resilience will show a stronger inverse relationship to negative parenting practices, as compared to individuals with the same number of ACEs but lower levels of resilience.

3. The relationship will hold when controlling for the manner in which subjects were themselves parented.

\section{Methodology}

\section{Participants}


Participants for this study (N=301) were recruited from Amazon's Mechanical Turk (MTurk) online platform pool of registered participants. The MTurk settings for this study restricted participation only to those who were from the United States and who were 18 years or older. In addition, it required all participants to have at least one child, whether biological or adopted, under the age of 18 years old currently living in their household. A link to Limesurvey was provided on MTurk, which directed participants to the study. An a priori power analysis indicated a minimum of 102 subjects were needed for the study to have $90 \%$ power for detecting a moderate sized effect set at a 0.05 criterion of statistical significance. Each participant was compensated \$0.13, distributed to them through MTurk, for completing the 45-minute study. The study's researchers created an account through MTurk and deposited the funds that were drawn from to compensate the participants.

\section{Demographics}

Although 368 subjects participated in this study, data was only utilized from the 301 participants that correctly answered a quality control question. Out of the 301 participants, $31.2 \%$ were male and $68.8 \%$ were female. A majority of the participants ethnically identified as White $(66.8 \%)$ with the remaining participants identifying as Black (11\%), Hispanic (7.6\%), Asian (7.3\%), multiple (5.6\%), American Indian (1.3\%), and Other (0.3\%). All of the participants had at least one child and almost all (90\%) participants indicated that the children currently living in their household were biologically related to them. Regarding marital status, $68.4 \%$ were currently married while $31.6 \%$ were not. Within this sample, $19.6 \%$ of participants reported annual salaries below $\$ 29,999,37.2 \%$ reported salaries between $\$ 30,000$ and $\$ 59,999,18.9 \%$ reported salaries between $\$ 60,000$ and $\$ 89,999$, and $24.2 \%$ reported salaries above $\$ 90,000$. Essentially half (49.8\%) of the participants considered themselves to be a member of an 
organized religious group with the other half of participants $(50.2 \%)$ not. Of those that considered themselves to be a member of an organized religious group, 23.6\% were Roman Catholic, 22.6\% were Protestant, 19.3\% indicated Nothing in Particular, 13.3\% indicated they were Something Else, 8\% indicated Atheist, 7.3\% were Agnostic, 2.7\% were Muslim, 1\% were Orthodox, $0.7 \%$ were Mormon, $0.7 \%$ were Jewish, $0.7 \%$ were Buddhist, and $0.3 \%$ were Hindu. Over one third (37.5\%) of the participants were college graduates.

\section{Measures}

\section{Adverse Childhood Experience (ACEs) Questionnaire}

The Adverse Childhood Experience (ACEs) Questionnaire contains 10 items that were used to assess adverse childhood experiences (e.g. abuse and neglect) and family/household dysfunction (e.g. domestic violence and substance abuse by parents or other household members). All of the items (e.g. "Did a parent or other adult in the household often push, grab, slap, or throw something at you" or "Were your parents ever separated or divorced") pertain to an individual's first 18 years of life. Each item on the scale was answered with a "yes", representing one point, or a "no", representing zero points. The total score for this scale was based on the total number of "yes" responses. According to Murphy and colleagues (2014), the Cronbach's alpha for this scale is .88 , demonstrating strong reliability. In this study, the ACEs Questionnaire had a Cronbach's alpha of .80, demonstrating good reliability.

\section{2-item Perceptions of Parents Scale (POPS)}

The Perceptions of Parents Scale (POPS) contains 42 items, 21 mother items and 21 father items, that were used to assess the degree to which parents provided an optimal parenting context. All of the items (e.g "My mother/father accepts me and likes me", "My mother/father 
spends a lot of time with me", "My mother/father isn't very sensitive to many of my needs") were rated on a 7-point Likert scale ranging from 1 (not at all true) to 7 (very true). There were six subscales: mother autonomy support ( 9 items), mother involvement (6 items), mother warmth (6 items), father autonomy support (9 items), father involvement (6 items), and father warmth (6 items). This scale demonstrates good reliability with a Cronbach's alpha of 0.938 (Niemiec, Ryan, \& Deci, 2009; Wintre \& Yaffe, 1991). In this study, the POPS had a Cronbach's alpha of .956 (mother 1)/.952 (father 1), demonstrating strong reliability.

\section{2-item Alabama Parenting Questionnaire (APQ)}

The Alabama Parenting Questionnaire (APQ) contains 42 items that were used to assess the quality of subjects' current parenting practices. All of the items (e.g. "You threaten to punish your child and then do not actually punish him/her", "You reward or give something extra to your child for obeying you or behaving well", "Your child is at home without adult supervision") were rated on a 5-point Likert scale ranging from 1 (never) to 5 (always). There were 5 subscales: positive involvement with children (10 items), poor monitoring/supervision, (10 items) use of positive parenting techniques ( 6 items), inconsistent discipline (6 items), and use of corporal punishment ( 3 items); there were 7 additional items that measured other discipline practices but were not categorized as an additional subscale. According to Essau, Sasagawa, and Frick (2006), the reliability scores are as follows: .75 (positive involvement), .59 (poor monitoring/supervision), .77 (positive parenting techniques), .73 (inconsistent discipline), and .55 (corporal punishment). In this study, the Cronbach's alphas for the APQ subscales are as follows: .88 (positive involvement), .84 (positive parenting), .94 (poor monitoring/supervision), .81 (inconsistent discipline), and .77 (corporal punishment). 


\section{6-item Parenting Stress Index-Short Form (PSI-SF)}

The Parenting Stress Index-Short Form (PSI-SF) is a brief version of the Parenting Stress Index (Abidin, 1995), a widely used measure of parenting stress. The PSI-SF was used to measure parental stress by examining parent focused, parent-child interaction focused, and child focused sources of stress. The PSI-SF contained 36 items (e.g. "I feel trapped by my responsibilities as a parent", "I have a child that rarely does things for me that make me feel good", "I have a child who is not able to do as much as I expected") which were rated on a 5point Likert scale ranging from 1 (strongly agree) to 5 (strongly disagree). There were three subscales: parental distress, parent-child dysfunctional interaction, and difficult child. Higher scores on the scale were indicative of higher parenting stress and poorer parenting practices. According to the Parental Stress Index, Short Form (n.d.), the scale demonstrates good internal reliability (.85) and stability over time (.76). The reliability scores for the subscales are as follows: .87 (parental distress), .80 (parent-child dysfunctional interaction), and .85 (difficult child). In this study, total stress was calculated with a Cronbach's alpha of .945, demonstrating excellent reliability.

\section{0-Item Connor-Davidson Resilience Scale (CD-RISC 10)}

The Connor-Davidson Resilience Scale (CD-RISC 10) contains 10 items that were used to measure resilience, or how well an individual can effectively cope with adversity. All of the items were answered according to how much the subject felt the statement applied to them over the last month. All items (e.g. "I am able to adapt when changes occur", "Having to cope with stress can make me stronger", "I am able to handle unpleasant or painful feelings like sadness, fear, and anger") were rated on a 5-point Likert scale ranging from 0 (not true at all) to 4 (true 
nearly all the time). The total score for resilience was calculated by summing all 10 items, with higher scores indicating higher resilience. The scale had a reliability score of .85 , indicating good reliability (Campbell-Sills, Forde, \& Stein, 2009; Davidson \& Connor, 2018). In this study, the CD-RISC 10 had a Cronbach's alpha of .91, demonstrating strong reliability.

\section{Procedure}

This study utilized a non-experimental, exploratory survey design. After obtaining IRB approval (IRB \#18-142), the MTurk survey link for the study was activated in a Limesurvey 3.15.9+ installation. Once the study was selected, participants read an informed consent form. This form notified subjects about the nature of the study; the number of questionnaires to be completed; the time required to complete them; any known risks involved and the consequences of failing to complete the study once started; that responses would be kept confidential; and that all participants included in this study must be 18 years or older and have at least one child, biological or adopted, currently under the age of 18 living in their household. After reading the informed consent form, participants gave their informed consent through an electronic signature. Participants then completed the demographic questionnaire as well as the 5 study questionnaires through Limesurvey. Once participants completed all measures, they submitted a randomly generated survey code to MTurk to indicate that the study had been completed to receive monetary compensation (\$0.13). The study took approximately 45 minutes to complete.

Measures were presented in the order indicated in the following table: 


\begin{tabular}{|c|c|c|c|}
\hline Measure & Variable & Source & $\begin{array}{c}\text { Number of } \\
\text { Items }\end{array}$ \\
\hline Demographics & --- & --- & 12 \\
\hline $\begin{array}{c}\text { Adverse Childhood } \\
\text { Experience (ACEs) } \\
\text { Questionnaire }\end{array}$ & $\begin{array}{c}\text { Adverse childhood } \\
\text { experiences }\end{array}$ & Murphy et al., 2014 & 10 \\
\hline $\begin{array}{c}\text { Perceptions on Parents } \\
\text { Scale (POPS) }\end{array}$ & Parenting & Robbins, 1994 & 21 items for \\
\hline $\begin{array}{c}\text { Alabama Parenting } \\
\text { Questionnaire (APQ) }\end{array}$ & $\begin{array}{c}\text { Quality of current } \\
\text { parenting practices }\end{array}$ & Essau et al., 2006 & 42 \\
\hline $\begin{array}{c}\text { Parenting Stress-Index } \\
\text { Short Form (PSI-SF) }\end{array}$ & Parental stress & Abidin, 1995 & 36 \\
\hline $\begin{array}{c}\text { Connor-Davidson } \\
\text { Resilience Scale (CD- } \\
\text { RISC 10) }\end{array}$ & Resilience & $\begin{array}{c}\text { Campbell-Sills et al., } \\
2007 \text { Davidson \& } \\
\text { Connor, 2018 }\end{array}$ & \\
\hline
\end{tabular}

The Perception of Parents Scale (POPS) was presented for both maternal and paternal figures. Prior to the POPS being given, subjects were asked if they grew up with none, one, or two maternal/paternal figures. They were administered the POPS according to the number of maternal/paternal figures they grew up with in their household.

\section{Analytical Approach}

As previously noted, this study examined the predicting relationship between adverse childhood experiences and the quality of current parenting practices while controlling for demographics and the manner in which subjects were parented. Before conducting any data analysis procedures, the ACEs and resilience (CD-RISC 10) variables were centered to allow for easier interpretation (Iacobucci, Schneider, Popovich, \& Bakamitsos 2017; Shieh, 2011). A 
seven-stage nested hierarchical multiple regression was used to assess the ability of adverse childhood experiences to predict current parenting practices (APQ), after controlling for other factors. Marital status, age, income, and gender were entered in stage one of the regression to control for general demographic variables. Subjects' membership within an organized religion, their frequency of attending religious services, and the importance of religion in their life were entered in stage two to control for religiosity. Subjects' perception of their maternal/paternal figures (POPS) were entered in stage three; adverse childhood experiences (ACEs Questionnaire) were entered in stage four; resilience (CD-RISC 10) was entered in stage five; the interaction between ACEs and resilience was entered in stage six; and parental stress (PSI-SF) was entered in stage seven. The variables were entered in this order according to the assumption that demographic variables and retrospective experiences are considered more stable and unchangeable whereas current parental stress appears to be more dynamic, variable, and malleable.

\section{Results}

\section{Predicting the Quality of Parenting Practices}

For positive parental involvement (Table 1), the nested hierarchical multiple regression revealed that at stage one $\left(\mathrm{R}^{2}=10 \%\right)$, gender significantly predicted positive parental involvement, $F(4,260)=7.55, p<.001$, with females having higher scores. Introducing the religion variables explained an additional $4.8 \%$ of the variance in positive parental involvement, $F(3,257)=4.92, p=.002$ Introducing subjects' perception of their parents explained an additional $2.1 \%$ of the variance, $F(2,255)=3.26, p=.04$. Adding adverse childhood experiences explained an insignificant additional $0.9 \%$ of the variance, $F(1,254)=2.76, p=.098$. Notably, 
adding resilience explained an additional $11.9 \%$ of the variance, $F(1,253)=43.10, p<.001$, while adding the interaction between ACEs and resilience explained an additional $1.1 \%$ of the variance, $F(1,252)=3.92, p=.049$. Finally, the addition of parental stress to the regression model explained an additional $1.4 \%$ of the variance in positive parental involvement, $F(1,251)=$ $5.22, p=.023$. When all variables were included within the regression model, marital status, gender, the frequency that subjects attended religious services, resilience, and parental stress were all significant unique predictors of positive parental involvement (see Table 1). The final model accounted for a total of $32.6 \%$ of the variance in positive parental involvement.

For positive parenting (Table 2), the nested hierarchical multiple regression revealed that at stage one $\left(\mathrm{R}^{2}=9 \%\right)$, income and gender significantly predicted positive parental involvement, $F(4,260)=6.74, p<.001$, with females and individuals with a higher income having higher scores. Introducing the religion variables explained an additional $4.9 \%$ of the variance in positive parenting, $F(3,257)=4.88, p=.003$. Introducing subjects' perception of their parents explained an additional $3.3 \%$ of the variance, $F(2,255)=5.15, p=.006$. Adding adverse childhood experiences explained an additional $1.5 \%$ of the variance, $F(1,254)=4.76, p=.03$. Notably, adding resilience explained an additional $10 \%$ of the variance, $F(1,253)=35.56, p<.001$, but adding the interaction between ACEs and resilience explained only an additional $0.6 \%$ of the variance, $F(1,252)=2.29, p=.131$. Finally, the addition of parental stress to the regression model explained an additional $1.4 \%$ of the variance in positive parenting, $F(1,251)=5.10, p=$ .025 . When all variables were included within the regression model, marital status, gender, subjects' membership within an organized religion, subjects' perceptions of their maternal figure, resilience, and parental stress were all significant predictors of positive parenting (see Table 2). The final model accounted for a total of $31.1 \%$ of the variance in positive parenting. 
For poor monitoring/supervision (Table 3), the nested hierarchical multiple regression revealed that at stage one $\left(\mathrm{R}^{2}=13 \%\right)$, age and gender significantly predicted poor monitoring/supervision, $F(4,260)=10.04, p<.001$, with older individuals and females having lower scores. Introducing the religion variables explained an insignificant additional $2.2 \%$ of the variance in poor monitoring/supervision, $F(3,257)=2.27, p=.081$. Introducing subjects' perception of their parents explained an additional $2.6 \%$ of the variance, $F(2,255)=4.06, p=$ .018. Adding adverse childhood experiences explained an additional 1.3\% of the variance, $F(1,254)=4.10, p=.044$. Adding resilience explained an additional $1.5 \%$ of the variance, $F(1,253)=4.81, p=.029$. Adding the interaction between ACEs and resilience explained an insignificant additional $0.3 \%$ of the variance, $F(1,252)=1.10, p=.296$. Finally, the addition of parental stress to the regression model explained an additional $32.5 \%$ of the variance in poor monitoring/supervision, $F(1,251)=176.61, p<.001$. When all variables were included within the regression model, gender and parental stress were significant predictors of poor monitoring/supervision (see Table 3). The final model accounted for a total of $53.8 \%$ of the variance in positive parenting.

For inconsistent discipline (Table 4), the nested hierarchical multiple regression revealed that at stage one $\left(\mathrm{R}^{2}=5 \%\right)$, age and gender significantly predicted inconsistent discipline, $F(4,260)=3.13, p=.015$, with older individuals and females having lower scores. Introducing the religion variables explained an additional $3.7 \%$ of the variance in inconsistent discipline, $F(3,257)=3.44, p=.018$. Introducing subjects' perception of their parents explained an insignificant additional $0.5 \%$ of the variance, $F(2,255)=0.74, p=.478$. Adding adverse childhood experiences explained an additional $1.5 \%$ of the variance, $F(1,254)=4.10, p=.044$. Adding resilience explained an additional $1.6 \%$ of the variance, $F(1,253)=4.57, p=.033$. 
Adding the interaction between ACEs and resilience explained an insignificant additional $0.8 \%$ of the variance, $F(1,252)=2.23, p=.137$. Finally, the addition of parental stress to the regression model explained an additional $35.5 \%$ of the variance in inconsistent discipline, $F(1,251)=171.51, p<.001$. When all variables were included within the regression model, gender, the importance of religion, and parental stress were all significant predictors of inconsistent discipline (see Table 4). The final model accounted for a total of $48.1 \%$ of the variance in inconsistent discipline.

For corporal punishment (Table 5), the nested hierarchical multiple regression revealed that at stage one $\left(\mathrm{R}^{2}=8 \%\right)$, age and gender significantly predicted inconsistent discipline, $F(4,260)=5.61, p<.001$, with older individuals and females having lower scores. Introducing the religion variables explained an insignificant additional $1.3 \%$ of the variance in corporal punishment, $F(3,257)=1.24, p=.295$. Introducing subjects' perception of their parents explained an additional $4.0 \%$ of the variance, $F(2,255)=5.82, p=.003$. Adding adverse childhood experiences explained an additional $1.8 \%$ of the variance, $F(1,254)=5.37, p=.021$. Adding resilience explained an insignificant additional $0.7 \%$ of the variance, $F(1,253)=2.08, p$ $=.151$. Adding the interaction between ACEs and resilience explained an additional $2.3 \%$ of the variance, $F(1,252)=7.01, p=.009$. Finally, the addition of parental stress to the regression model explained an additional $40.5 \%$ of the variance in inconsistent discipline, $F(1,251)=$ $245.15, p<.001$. When all variables were included within the regression model, age, the interaction between ACEs and resilience, and parental stress were all significant predictors of corporal punishment (see Table 5). However, the magnitude of the interaction between ACEs and resilience was small despite being significant (see Figure 1). The final model accounted for a total of $58.5 \%$ of the variance in corporal punishment. 


\section{Discussion}

This study investigated the relationship between adverse childhood experiences and the quality of current parenting practices. It also examined the role of resilience as a protective factor within this relationship while controlling for other variables. Surprisingly, results did not support ACEs as being a significant predictor for parenting practices, either positive or negative, when controlling for other factors. However, results suggested that resilience is a consistent predictor of positive parenting practices (e.g. positive parental involvement and positive parenting) and parental stress is a consistent predictor of negative parenting practices (e.g. poor monitoring/supervision, inconsistent discipline, and corporal punishment), even when controlling for other factors including ACEs. Furthermore, resilience appeared to significantly interact with ACEs when examining corporal punishment, but it did not appear to have the protective quality that was emphasized by previous research. Instead, higher resilience appeared to increase individuals' use of corporal punishment, especially for individuals who had experienced more ACEs.

This finding that ACEs do not explain unique variance in parenting practices is contrary to previous research which emphasizes how the physical, psychological, and emotional consequences of early childhood trauma can extend into later years of life (Chartier et al., 2010; Felitti et al., 1998; Resier et al., 2014) and cause abusive parenting tendencies in adulthood (Belsky, 1984). On the other hand, parental stress was found to be a substantial direct predictor of negative parenting practices (poor monitoring/supervision, inconsistent discipline, and corporal punishment). In order to make sense of these findings, it is important to note the close relationship between ACEs and subsequent stress. Research has shown that traumatic childhood experiences can have an adverse effect on a variety of crucial biological functions, ultimately 
resulting in the dysregulation of the stress-response system. For example, biological mechanisms related to toxic stress, such as processes involving the hypothalamic-pituitary adrenocortical (HPA) axis, become dysregulated over time due to toxic stress (Shonkoff et al., 2012). Rather than recovering from these large amounts of toxic stress, the body is inhibited from returning to a homeostatic balance. When an individual's stress system has been burdened to this extent, their body cannot effectively regulate normal stress-responses. Therefore, childhood trauma and the frequent exposure to toxic stress associated with it cause "cumulative damage over time" and prevent the ability to effectively cope with subsequent stressful experiences (Shonkoff, Boyce, \& McEwen, 2009, p. 2252).

Due to the extreme toxic stress experienced in childhood and the dysregulation of the stress system, the normal experience of parenting (which can already be stressful to someone with a well-regulated stress system) may become overwhelmingly stressful to a victim of ACEs. In essence, the stress caused by ACEs is continuously compounding into adulthood and culminating into large amounts of parental stress. As my research demonstrated, these high levels of stress are resulting in the use of negative parenting practices. Therefore, it is reasonable to assume that individuals who have experienced ACEs will find it more difficult to deal with the stress of parenting which may result in the use of negative parenting practices that would continue the cycle of stress-inducing childhood trauma. If this is true, the correlation between ACEs and parenting practices should be heavily mediated by parental stress. In order to test this idea, I conducted a post hoc mediation effect size analysis (Preacher \& Kelley, 2011) which revealed that this was, in fact, the case: parental stress was accounting for moderate to large mediation effect sizes between ACEs and negative parenting practices (poor monitoring/supervision: $\kappa^{2}=.182,95 \%$ CI[.098, .267], inconsistent discipline: $\kappa^{2}=.183,95 \%$ 
CI[.102, .273], corporal punishment: $\left.\mathrm{K}^{2}=.208,95 \% \mathrm{CI}[.116, .300]\right)$. Although parental stress explained only trivial to small amounts of the relationship between ACEs and positive parenting practices (positive parental involvement: $\kappa^{2}=.066,95 \%$ CI[.003, .115], positive parenting: $\kappa^{2}=$ $.071,95 \% \mathrm{CI}[.003, .121])$, this is not surprising considering the fact that parental stress only accounted for a very small amount of the variance in positive parenting outcomes as opposed to that in negative parenting outcomes. These findings suggest that although there is not a direct relationship between ACEs and current parenting practices, ACEs are manifesting themselves in dysregulated stress responses that culminate in high levels of parental stress which result in poor parenting practices.

Beyond highlighting the crucial role that parental stress plays in predicting negative parenting outcomes, this study also demonstrated the positive influence that resilience has on encouraging the use of positive parenting practices (practices such as volunteering to help with activities that your child is involved in, telling your child when they are doing a good job with something, rewarding your child for good behavior, and playing games with your child). Literature explains this relationship between resilience and positive parenting by focusing on how key aspects of resilience (such as social support, social and emotional competence, and knowledge of parenting and child development) help an individual heal from the adversity they faced. Multiple studies have shown that social support, especially in the form of a single trusted adult in childhood, can improve resilience and substantially mitigate many of the harmful consequences of ACEs (Bellis et al., 2017; Cheong, Sinnott, Dahly, \& Kearney, 2017; LoganGreene et al., 2013; Woods-Jaeger, Cho, Sexton, Slagel, \& Goggin, 2018). Having these stable and committed relationships with family and friends allows for a support system during difficult times. In addition to social support, social and emotional competence can help a victim of 
childhood trauma not only understand their thoughts and feelings, but learn how to express and process them in a healthy way without accumulating stress or later turning to harmful coping mechanisms like abusive parenting. Finally, educating parents on child development and effective parenting strategies can play a huge role in creating less stressed and more equipped parents.

Despite our expected finding that resilience would increase positive parenting practices, results revealed one anomaly that contradicted virtually all previous literature which promoted resilience as a protective factor: individuals with high ACEs and high levels of resilience used corporal punishment more than individuals with high ACEs and low levels of resilience. A potential explanation for this finding requires the willingness to see resilience in a new light; to see the dark side of resilience. Charmorro-Premuzic and Lusk (2017) explain how extreme resilience can drive individuals to hold unrealistic expectations. Furthermore, these individuals become persistent on reaching these unattainable goals, leading to a phenomenon known as "false hope syndrome". Despite clear signs that their expectations are likely to be met, they waste large amounts of optimism and energy believing they will be. The more they demand for these expectations to be met, the more they become intolerant of unpleasant or counterproductive circumstances.

Now, imagine this in the parenting context: a parent has set unrealistically high expectations for their child, but rather than meeting these expectations, their child is rebelling against them. With emotional/psychological exhaustion to fuel their decision-making, the parent resorts to the parenting strategy that was foundational during their childhood years: physical punishment. Although this is a valid, possible explanation for our findings, it is important to note that the overall use of corporal punishment within our sample was low. Subjects falling one 
standard deviation below and one standard deviation above the sample mean were indicating that they used corporal punishment "almost never" to "sometimes". Because of this, we do not believe this unexpected finding negates the importance of resilience in increasing the use of positive parenting practices.

\section{Limitations}

Although this study was well-constructed and ethically executed, it is important to note some potential limitations. First, this study relied on a sample of Amazon MTurk participants who are very familiar with the survey-taking process. This may be seen as a positive because participants are more likely used to being introspective and that is rated for their online work, therefore leading to more accurate self-reporting. At the same time, MTurk participants are also anonymous and not directly interacting with the researcher. In the latter case, there is an unknowable but assumed proportion of the sample that is not completing the survey in good faith. Of course, malingering can also be a problem with in-person data collection as well.

Second, a majority of the participants $(66.8 \%)$ within this sample identified as White. Previous research has found ethnic differences in the number of ACEs endured (Dube, Anda, Felitti, Edwards, \& Croft, 2002), suggesting that the prevalence of ACEs is the lowest among Asian individuals and the highest among Black individuals. Due to these findings, the generalizability of our results may be more limited to a White population. However, in my sample, there were no substantial differences in the number of ACEs experienced between Whites and non-Whites.

Third, this study was limited by retrospective, self-reporting from the participants regarding their adverse childhood experiences and the parental environment in which they were 
raised. Because participants were asked to think back to their childhood which, for some participants, could be over 50 years ago, their recollection of events and emotions during this time of their life may have been biased or incomplete. Future work could examine these concepts longitudinally as to avoid such limitations. However, a project of that scope was not possible for the timeframe and accessible resources of this current study.

Finally, there were limitations to the construct used to measure adverse childhood experiences. The ACEs Questionnaire simply asked "yes/no" response questions, allowing for a measure of the number of ACEs experienced by a participant. However, the questionnaire did not allow the participants to indicate the frequency of their experiences or their feelings about the experiences (i.e. whether they would still consider that experience to be traumatizing, how often they have thought about that experience since the event, etc.). Because of this, the measurement of ACEs was limited simply to the number of ACEs experienced by a participant and did not allow for more broad explanations regarding the findings. Future research should focus on utilizing a more detailed ACEs construct that takes into account these various aspects of childhood trauma in order to provide a more holistic understanding of this concept.

\section{Implications}

This study revealed an intergenerational trauma cycle in which childhood trauma is passed down through negative parenting practices. Unfortunately, to date it seems to be difficult to change or reverse the childhood trauma that an individual experienced. ACEs are stable and unless they are addressed soon after occurring, their negative effects will trickle down into later years of life. These negative effects include issues such as conduct problems, aggression, depression, anxiety, substance abuse, and academic difficulties (Carpenter, 2016). I have argued 
that these consequences perpetuate through adolescence and into adulthood, ultimately manifesting themselves as domestic violence, continued substance abuse, and parental stress. As demonstrated by this study, parental stress turns into problematic parenting and the cycle continues. This process not only negatively impacts the individual who has been traumatized, but also puts their own children at risk for experiencing trauma as well.

Thankfully, unlike ACEs, parental stressors are dynamic; stress levels can be changed. Educating parents on how to improve emotional regulation, develop communication strategies, effectively resolve conflicts, and promote self-esteem and assertiveness can increase parenting competency. If a parent feels more confident and well-equipped to handle difficult and stressful parenting situations, their overall parental stress will decrease and their effective parenting strategies that they have learned can take over. Research has shown that various parenting programs that focus on these aspects of parenting have had beneficial outcomes (Sanders, 2003; Wolfe, Sandler, \& Kaufman, 1981). For example, the Program-Guide to Develop Emotional, Educational, and Parenting Competencies resulted in reduced substantiated cases of abuse, outof-home placements, and injuries due to maltreatment (Martinez-Gonzalez, Rodriguez-Ruiz, Alvarez-Blanco, \& Becedoniz-Vazquez, 2016). Parents who successfully completed another parenting program, known as the Nobody's Perfect Program, demonstrated an increase in warm/positive parent-child interactions, sense of parenting competency/satisfaction, and effective child management skills. Furthermore, the program resulted in less angry and punitive parenting (Chislett \& Kennett, 2006). Through parenting programs such as these that seek to improve parenting competencies, parents will be more equipped to appropriately deal with the natural stress that comes with parenting, resulting in positive parenting practices that can break the intergenerational cycle of childhood trauma. 


\section{References}

Abidin, R. R. (1995). Parenting Stress Index, Third Edition: Professional Manual. Odessa, FL: Psychological Assessment Resources, Inc.

Anda, R. F., Whitfield, C. L., Felitti, V. J., Chapman, D., Edwards, V. J., Dube, S. R., \& Williamson, D. F. (2002). Adverse childhood experiences, alcoholic parents, and later risk of alcoholism and depression. Psychiatric Services, 53(8), 1001-1009. Doi: 10.1176/appi.ps.53.8.1001

Bellis, M. A., Hardcastle, K., Ford, K., Hughes, K., \& Ashton, K. (2017). Does continuous trusted adult support in childhood impart life-course resilience against adverse childhood experiences-a retrospective study on adult health-harming behaviours and mental wellbeing. BMC Psychiatry, 17(1), 1-12. Doi: 10.1186/s12888-017-1260-z

Belsky, J. (1984). The determinants of parenting: A process model. Child Development, 5(1), 8396. Doi: $10.2307 / 1129836$

Bertina Carpenter. (2016). The impact of adverse childhood experiences across the lifespan [video file]. Retrieved from https://slideplayer.com/slide/9128977/

Burnett, H. \& Wahl, K. (2015). The compassion fatigue and resilience connection: A survey of resilience, compassion fatigue, burnout, and compassion satisfaction among trauma responders. International Journal of Emergency Mental Health and Human Resilience, 17(1), 318-326. Doi: 10.4172/1522-4821.1000

Campbell-Sills, L., Forde, D. R., \& Stein, M. B. (2009). Demographic and childhood environmental predictors of resilience in a community sample. Journal of Psychiatric Research, 43(12), 1007-1012. Doi: 10.1016/j.jpsychires.2009.01.013 
Chamorro-Premuzic, T. \& Lusk, D. (2017). The dark side of resilience. Harvard Business Review. Retrieved from https://hbr.org/2017/08/the-dark-side-of-resilience

Champagne, F. A. \& Meaney, M. J. (2001). Like mother, like daughter: evidence for nongenomic transmission of parental behavior and stress responsivity. Progress in Brain Research, 133, 287-302. Doi: 10.1016/S0079-6123(01)33022-4

Champagne, F. A. \& Meaney, M. J. (2006). Stress during gestation alters postpartum maternal care and the development of the offspring in a rodent model. Biological Psychiatry, 59(12), 1227-1235. Doi: 10.1016/j.biopsych.2005.10.016

Chapman, D. P., Whitfield, C. L., Felitti, V. J., Dube, S. R., Edwards, V. J., \& Anda, R. F. (2004). Adverse childhood experiences and the risk of depressive disorders in adulthood. Journal of Affective Disorders, 82(2), 217-215. Doi: 10.1016/j.jad.2003.12.013

Chartier, M. J., Walker, J. R., \& Naimark, B. (2010). Separate and cumulative effects of adverse childhood experiences in predicting adult health and health care utilization. Child Abuse and Neglect, 34(6), 454-464. Doi: 10.1016/j.chiabu.2009.09.020

Cheong, E., Sinnott, C., Dahly, D., \& Kearney, P. M. (2017). Adverse childhood experiences (ACEs) and later-life depression: perceived social support as a potential protective factor. BMJ Open, 7(9). Doi: 10.1136/bmjopen-2016-013228

Chislett, G. \& Kennett, D. J. (2006). The effects of the Nobody's Perfect Program on parenting resourcefulness and competency. Journal of Child and Family Studies, 16(4), 473-482. Doi: 10.1007/s10826-006-9098-x

Cooper, J. L., Masi, R., \& Vick, J. (2009). Social-emotional development in early childhood: What every policymaker should know. Retrieved from the National Center for Children in 
Poverty, Mailman School of Public Health, Columbia University from https://academiccommons.columbia.edu/catalog/ac:126269

Davidson, J. R. T. \& Connor K. M. Connor-Davidson Resilience Scale (CD-RISC) Manual. Unpublished. 01-01-2018 and partly accessible at www.cd-risc.com

De Bellis, M. D., Woolley, D. P., \& Hooper, S. R. (2013). Neuropsychological findings in pediatric maltreatment: Relationship of PTSD, dissociative symptoms, and abuse/neglect indices to neurocognitive outcomes. Child Maltreatment 18(3), 171-183. Doi:

$10.1177 / 1077559513497420$

Dube, S. R., Anda, R. F., Felitti, V. J., Edwards, V. J., \& Croft, J. B. (2002). Adverse childhood experiences and personal alcohol abuse as an adult. Addictive Behaviors, 27(5), 713-725. Doi: 10.1016/S0306-4603(01)00204-0

Enlow, M. B., Egeland, B., Blood, E. A., Wright, R. O., \& Wright, R. J. (2012). Interpersonal trauma exposure and cognitive development in children to age 8 years: A longitudinal study. Journal of Epidemiology \& Community Health, 66(11). Doi: 10.1136/jech-2011200727

Essau, C. A., Sasagawa, S., \& Frick, P. J. (2006). Psychometric properties of the Alabama Parenting Questionnaire. Journal of Child and Family Studies, 15(5), 595-614. Doi: $10.1007 /$ s10826-006-9036-y

Everly, G.S., Welzant, V., \& Jacobson, J.M. (2008). Resistance and resilience: the final frontier in traumatic stress management. International Journal of Emergency Mental Health, 10(4), 261-270.

Felitti, V. J., Anda, R. F., Nordenberg, D., Williamson, D. F., Spitz, A. M., Edwards, V., Koss, M. P., \& Marks, J. S. (1998). Relationship of childhood abuse and household dysfunction 
to many of the leading causes of death in adults: The adverse childhood experiences (ACE) study. American Journal of Preventive Medicine, 14, 245-258. Doi: $10.1016 / \mathrm{S} 0749-3797(98) 00017-8$

Hawkins, J. D., Kosterman, R., Catalano, R. F., Hill, K. G., \& Abbott, R. D. (2005). Promoting positive adult functioning through social development intervention in childhood: longterm effects from the seattle social development project. Archives of Pediatrics and Adolescent Medicine, 159(1), 25-31. Doi: 10.1001/archpedi.159.1.25

Iacobucci, D., Schneider, M. J., Popovich, D. L., \& Bakamitsos, G. A. (2017). Mean centering, multicollinearity, and moderators in multiple regression: The reconciliation redux. Behavior Research Methods, 49(1), 403-404. Doi: 10.3758/s13428-016-0827-9

Kalmakis, K.A. \& Chandler, G. E. (2014). Adverse childhood experiences: towards a clear conceptual meaning. Journal of Advanced Nursing, 70(7), 1489-1501. Doi: $10.1111 /$ jan. 12329

Kestila, L., Martelin, T., Rahkonen, O., Joutsenniemi, K., Pirkola, S., Poikolainen, K., \& Koskinen, S. (2008). Childhood and current determinants of heavy drinking in early adulthood. Alcohol and Alcoholism, 43(4), 460-469. Doi: 10.1093/alcalc/agn018

Lansford, J. E., Dodge, K. E., Pettit, G. S., Bates, J. E., Crozier, J., \& Kaplow, J. (2002). A $12-$ year prospective study of the long-term effects of early child physical maltreatment on psychological, behavioral, and academic problems in adolescence. Archives of Pediatrics \& Adolescent Medicine, 156, 824-830.

Logan-Greene, P., Green, S., Nurius, P. S., \& Longhi, D. (2013). Distinct contributions of adverse childhood experiences and resilience resources: a cohort analysis of adult 
physical and mental health. Social Work in Health Care, 53(8), 776-797. Doi:

$10.1080 / 00981389.2014 .944251$

Martinez-Gonzalez, R. A., Rodriguez-Ruiz, B., Alvarez-Blanco, L., \& Becedoniz-Vazquez, C. (2016). Evidence in promoting positive parenting through the program-guide to develop emotional competences. Psychosocial Intervention, 25(2), 111-117. Doi:

10.1016/j.psi.2016.04.001

Middlebrooks, J. S. \& Audage, N. C. (2008). The effects of childhood stress on health across the lifespan. Retrieved from the Centers for Disease Control and Prevention, National Center for Injury Prevention and Control from http://healthequity.lib.umd.edu/932/1/Childhood_Stress.pdf

Moore, K. A. \& Ramirez, A. N. (2016). Adverse childhood experience and adolescent wellbeing: Do protective factors matter? Child Indicators Research, 9(2), 299-316. Doi: $10.1007 / \mathrm{s} 12187-015-9324-4$

Murphy, A., Steele, M., Dube, S. R., Bate, J., Bonuck, K., Meissner, P., Goldman, H., \& Steele, H. (2014). Adverse childhood experiences (ACEs) questionnaire and adult attachment interview (AAI): Implications for parent child relationships. Child Abuse and Neglect, 38(2), 224-233. Doi: 10.1016/j.chiabu.2013.09.004

National Scientific Council on the Developing Child. (2005). Excessive stress disrupts the architecture of the developing brain. (Working Paper No. 3). Retrieved from https://developingchild.harvard.edu/wpcontent/uploads/2005/05/Stress_Disrupts_Architecture_Developing_Brain-1.pdf 
Niemiec, C. P., Ryan, R. M., \& Deci, E. L. (2009). The path taken: Consequences of attaining intrinsic and extrinsic aspirations in post-college life. Journal of Research in Personality, 43, 291-306. Doi: 10.1016/j.jrp.2008.09.001

Parental Stress Index, Short Form. (n.d.). Retrieved from https://www.nctsn.org/measures/parenting-stress-index-short-form

Pechtel, P. \& Pizzagalli, DA. (2011). Effects of early life stress on cognitive and affective function: an integrated review of human literature. Psychopharmacology, 214(1), 55-70. Doi: $10.1007 / \mathrm{s} 00213-010-2009-2$

Poole, J. C., Dobson, K. S., \& Pusch, D. (2017). Childhood adversity and adult depression: The protective role of psychological resilience. Child Abuse and Neglect, 64, 89-100. Doi: 10.1016/j.chiabu.2016.12.012

Preacher, K. J. \& Kelley, K. (2011). Effect size measures for mediation models: quantitative strategies for communicating indirect effects. Psychological Methods, 12(2), 93-115. Doi: $10.1037 / \mathrm{a} 0022658$

Putallaz, M., Costanzo, P. R., Grimes, C. L., \& Sherman, D. M. (1998). Intergenerational continuities and their influences on children's social development. Social Development, 7(3), 389-427. Doi: 10.1111/1467-9507.00074

Randell, O’Malley, \& Dowd, M. D. (2015). Association of parental adverse childhood experiences and current child adversity. JAMA Pediatrics, 169(8), 786-787. Doi: 10.1001/jamapediatrics.2015.0269

Resier, S. J., McMillan, K. A., Wright, K. D., \& Asmundson, G. J. G. (2014). Adverse childhood experiences and health anxiety in adulthood. Child Abuse and Neglect, 38(3), 407-413. Doi: 10.1016/j.chiabu.2013.08.007 
Robbins, R. J. (1994). An assessment of perceptions of parental autonomy support and control: Child and parent correlates. Unpublished Doctoral Dissertation, Department of Psychology, University of Rochester, New York.

Sanders, M. (2003). Triple P-positive parenting program: A population approach to promoting competent parenting. Australian e-Journal for the Advancement of Mental Health, 2(3), 127-143. Doi: 10.5172/jamh.2.3.127

Shieh, G. (2011). Clarifying the role of mean centering in multicollinearity of interaction effects. British Journal of Mathematical and Statistical Psychology, 64, 462-477. Doi: 10.1111/j.2044-8317.2010.02002.x

Shonkoff, J. P., Boyce, W. T., \& McEwen, B. S. (2009). Neuroscience, molecular biology, and the childhood roots of health disparities: building a new framework for health promotion and disease prevention. Journal of the American Medical Association, 301(21), 22522259. Doi: $10.1001 /$ jama.2009.754

Shonkoff, J. P., Garner, A. S., and the Committee on Psychological Aspects of Child and Family Health, Committee on Early Childhood, Adoption, and Dependent Care, and Section on Developmental and Behavioral Pediatrics. (2012). The lifelong effects of early childhood adversity and toxic stress. American Academy of Pediatrics, 129(1), 232-246. Doi: 10.1542/peds.2011-2663

Soleimanpour, S., Geierstanger, S., \& Brindis, C. D. (2017). Adverse childhood experiences and resilience: addressing the unique needs of adolescents. Academic Pediatrics, 17(7), 108114. Doi: 10.1016/j.acap.2017.01.008

Van Ijzendoorn, M. H. (1992). Intergenerational transmission of parenting: A review of studies in nonclinical populations. Developmental Review, 12, 76-99. 
Wagnild, G., \& Young, H. (1993). Development and psychometric evaluation of the Resilience Scale. Journal of Nursing Measurement, 1(2), 165-178.

Wethington, H.R., Hahn, R.A., Fuqua-Whitley, D.S., Sipe, T. A., Crosby, A. E., Johnson, R. L., ...Task Force on Community Preventive Services. (2008). The effectiveness of interventions to reduce psychological harm from traumatic events among children and adolescents: a systematic review. American Journal of Preventative Medicine, 35(3): 287-313. Doi: 10.1016/j.amepre.2008.06.024

Whitaker, R. C., Dearth-Wesley, T., Gooze, R. A., Becker, B. D., Gallagher, K. C., McEwen, B. S. (2014). Adverse childhood experiences, dispositional mindfulness, and adult health. Preventive Medicine, 67, 147-153. Doi: 10.1016/j.ypmed.2014.07.029

Whitfield, C. L., Anda, R. F., Dube, S. R., \& Felitti, V. J. (2003). Violent childhood experiences and the risk of intimate partner violence in adults. Journal of Interpersonal Violence, 18(2), 166-185. Doi:n 10.1177\%2F0886260502238733

Wintre, M. G. \& Yaffe, M. (1991, April). Perception of parents scale: development and validation. Paper presented at the Biennial Meeting of Society for Research in Child Development, Seattle, WA.

Wolfe, D. A., Sandler, J. \& Kaufman, K. (1981). A competency-based parent training program for child abusers. Journal of Consulting and Clinical Psychology, 49(5), 633-640. Doi: 10.1037/0022-006X.49.5.633

Woods-Jaeger, B. A., Cho, B., Sexton, C. C., Slagel, L., \& Goggin, K. (2018). Promoting resilience: Breaking the intergenerational cycle of adverse childhood experiences. Health Education \& Behavior, 45(5), 772-780. Doi: 10.1177/1090198117752785 
Table 1. This table depicts the relationship between various predictors and positive parental involvement within a nested hierarchical regression.

Positive Parental Involvement

\begin{tabular}{|c|c|c|c|c|c|c|c|}
\hline & Stage 1 & Stage 2 & Stage 3 & Stage 4 & Stage 5 & Stage 6 & Stage 7 \\
\hline Married & 0.16 & 0.13 & 0.12 & 0.11 & 0.13 & 0.15 & $0.16^{*}$ \\
\hline Age & -0.00 & -0.00 & $-8.42 e-4$ & $-7.73 e-5$ & -0.00 & -0.00 & -0.00 \\
\hline Income & 0.02 & $0.03 * *$ & 0.03 & $0.03 *$ & 0.02 & 0.02 & 0.02 \\
\hline Female & $0.36 * * *$ & $0.38 * * *$ & $0.38 *$ & $-0.39 * * *$ & $0.37 * * *$ & $0.37 * * *$ & $0.36 * * *$ \\
\hline $\begin{array}{l}\text { Consider self a } \\
\text { member of an } \\
\text { organized religion }\end{array}$ & & $-0.27^{*}$ & $-0.25 *$ & $-0.25^{*}$ & $-0.22 *$ & $-0.21 *$ & -0.18 \\
\hline $\begin{array}{l}\text { Frequency of } \\
\text { attendance at religious } \\
\text { services }\end{array}$ & & $0.15^{* *}$ & $0.15 * *$ & $0.15 * *$ & $0.11^{*}$ & $0.10^{*}$ & $0.02 *$ \\
\hline Importance of religion & & -0.02 & -0.03 & -0.03 & -0.01 & -0.00 & -0.02 \\
\hline $\begin{array}{l}\text { Perception of maternal } \\
\text { figure }\end{array}$ & & & $0.06^{*}$ & $0.08 * *$ & 0.05 & 0.04 & 0.04 \\
\hline $\begin{array}{l}\text { Perception of paternal } \\
\text { figure }\end{array}$ & & & -0.01 & 0.02 & 0.01 & -0.00 & -0.00 \\
\hline
\end{tabular}

Adverse childhood

0.03

0.01

0.01

0.02

experiences

\begin{tabular}{|c|c|c|c|c|c|c|c|}
\hline Resilience & & & & & $0.33 * * *$ & $0.33 * * *$ & $0.30 * * *$ \\
\hline ACEs x Resilience & & & & & & $-0.04 *$ & -0.03 \\
\hline Parental Stress & & & & & & & $-0.12 *$ \\
\hline $\mathrm{R}^{2}$ & 0.10 & 0.15 & 0.17 & 0.18 & 0.30 & 0.31 & 0.33 \\
\hline $\mathrm{F}$ & $7.55^{* * *}$ & $6.62 * * *$ & $5.97 * * *$ & $5.68 * * *$ & $9.94 * * *$ & $9.55 * * *$ & $9.36 * * *$ \\
\hline$\Delta \mathrm{R}^{2}$ & & 0.05 & 0.02 & 0.01 & 0.12 & 0.01 & 0.01 \\
\hline $\mathrm{F}$ & & $4.92 * *$ & $3.26^{*}$ & 2.76 & $43.10 * * *$ & $3.92 *$ & $5.22 *$ \\
\hline
\end{tabular}

$* p<.05 ; * * p<.01 ; * * * p<.001$ 
Table 2. This table depicts the relationship between various predictors and positive parenting within a nested hierarchical regression.

Positive Parenting

\begin{tabular}{|c|c|c|c|c|c|c|c|}
\hline & Stage 1 & Stage 2 & Stage 3 & Stage 4 & Stage 5 & Stage 6 & Stage 7 \\
\hline Married & 0.16 & 0.14 & 0.12 & 0.12 & 0.13 & 0.15 & $0.16^{*}$ \\
\hline Age & $-8.06 \mathrm{e}-4$ & -0.00 & $-4.61 e-4$ & $5.60 \mathrm{e}-4$ & -0.00 & -0.00 & -0.00 \\
\hline Income & $0.03 *$ & $0.03 * *$ & 0.02 & $0.03 *$ & 0.02 & 0.02 & 0.02 \\
\hline Female & $0.36 * * *$ & $0.34 * * *$ & $0.34 * * *$ & $0.34 * * *$ & $0.33 * * *$ & $0.32 * * *$ & $0.32 * * *$ \\
\hline $\begin{array}{l}\text { Consider self a } \\
\text { member of an } \\
\text { organized religion }\end{array}$ & & $-0.40 * * *$ & $-0.36 * * *$ & $-0.37 * * *$ & $-0.34 * * *$ & $-0.33 * *$ & $-0.30 * *$ \\
\hline $\begin{array}{l}\text { Frequency of } \\
\text { attendance at religious } \\
\text { services }\end{array}$ & & 0.07 & 0.07 & 0.08 & 0.04 & 0.03 & 0.04 \\
\hline Importance of religion & & 0.08 & 0.08 & 0.06 & 0.09 & 0.09 & 0.08 \\
\hline $\begin{array}{l}\text { Perception of maternal } \\
\text { figure }\end{array}$ & & & $0.08 * *$ & $0.11 * * *$ & $0.07 *$ & $0.07 *$ & $0.06^{*}$ \\
\hline $\begin{array}{l}\text { Perception of paternal } \\
\text { figure }\end{array}$ & & & 0.01 & 0.03 & 0.01 & 0.01 & 0.01 \\
\hline
\end{tabular}

Adverse childhood

$\begin{array}{llll}0.04 * & 0.02 & 0.02 & 0.03\end{array}$
experiences

\begin{tabular}{|c|c|c|c|c|c|c|c|}
\hline Resilience & & & & & $0.31 * * *$ & $0.31 * * *$ & $0.28 * * *$ \\
\hline ACEs x Resilience & & & & & & -0.03 & -0.03 \\
\hline Parental Stress & & & & & & & $-0.12 *$ \\
\hline $\mathrm{R}^{2}$ & 0.09 & 0.14 & 0.18 & 0.19 & 0.30 & 0.30 & 0.31 \\
\hline $\mathrm{F}$ & $6.74 * * *$ & $6.11 * * *$ & $6.05 * * *$ & $6.00 * * *$ & $9.43 * * *$ & $8.88 * * *$ & $8.72 * * *$ \\
\hline$\Delta \mathrm{R}^{2}$ & & 0.05 & 0.03 & 0.02 & 0.10 & 0.01 & 0.01 \\
\hline $\mathrm{F}$ & & $4.88 * *$ & $5.15 * *$ & $4.76^{*}$ & $35.56 * * *$ & 2.29 & $5.10 *$ \\
\hline
\end{tabular}

$* p<.05 ; * * p<.01 ; * * * p<.001$ 
Table 3. This table depicts the relationship between various predictors and poor monitoring/supervision within a nested hierarchical regression.

Poor Monitoring/Supervision

\begin{tabular}{|c|c|c|c|c|c|c|c|}
\hline & Stage 1 & Stage 2 & Stage 3 & Stage 4 & Stage 5 & Stage 6 & Stage 7 \\
\hline Married & 0.19 & 0.16 & 0.19 & 0.18 & 0.17 & 0.15 & 0.06 \\
\hline Age & $-0.02 * * *$ & $-0.02 * *$ & $-0.02 * *$ & $-0.02 * *$ & $-0.02 * *$ & $-0.02 * *$ & -0.01 \\
\hline Income & -0.03 & -0.03 & -0.02 & -0.02 & -0.01 & -0.01 & -0.01 \\
\hline Female & $-0.61 * * *$ & $-0.55 * * *$ & $-0.54 * * *$ & $-0.53 * * *$ & $-0.52 * * *$ & $-0.52 * * *$ & $-0.47 * * *$ \\
\hline $\begin{array}{l}\text { Consider self a } \\
\text { member of an } \\
\text { organized religion }\end{array}$ & & 0.26 & 0.22 & 0.21 & 0.20 & 0.19 & 0.02 \\
\hline $\begin{array}{l}\text { Frequency of } \\
\text { attendance at } \\
\text { religious services }\end{array}$ & & 0.06 & 0.07 & 0.09 & 0.11 & 0.12 & 0.08 \\
\hline $\begin{array}{l}\text { Importance of } \\
\text { religion }\end{array}$ & & -0.05 & -0.04 & -0.05 & -0.07 & -0.07 & 0.03 \\
\hline $\begin{array}{l}\text { Perception of } \\
\text { maternal figure }\end{array}$ & & & $-0.08 *$ & -0.05 & -0.03 & -0.03 & -0.00 \\
\hline $\begin{array}{l}\text { Perception of paternal } \\
\text { figure }\end{array}$ & & & -0.05 & 0.03 & -0.02 & -0.01 & -0.01 \\
\hline
\end{tabular}

Adverse childhood

$0.05^{*} \quad 0.06 * \quad 0.06^{*} \quad 0.00$
experiences

Resilience

ACEs x Resilience

$-0.18^{*} \quad-0.17^{*} \quad 0.02$

\section{Parental Stress}

\begin{tabular}{llllllll}
\hline $\mathrm{R}^{2}$ & 0.13 & 0.16 & 0.18 & 0.20 & 0.21 & 0.21 & 0.54 \\
$\mathrm{~F}$ & $10.04 * * *$ & $6.80 * * *$ & $6.32 * * *$ & $6.16^{* * *}$ & $6.12 * * *$ & $5.71 * * *$ & $22.52 * * *$ \\
$\Delta \mathrm{R}^{2}$ & & 0.02 & 0.03 & 0.01 & 0.02 & 0.00 & 0.32 \\
$\mathrm{~F}$ & & 2.27 & $4.06^{*}$ & $4.10^{*}$ & $4.81 *$ & 1.10 & $176.61 * * *$ \\
\hline
\end{tabular}

$* p<.05 ; * * p<.01 ; * * * p<.001$ 
Table 4. This table depicts the relationship between various predictors and inconsistent discipline within a nested hierarchical regression.

Inconsistent Discipline

\begin{tabular}{|c|c|c|c|c|c|c|c|}
\hline & Stage 1 & Stage 2 & Stage 3 & Stage 4 & Stage 5 & Stage 6 & Stage 7 \\
\hline Married & 0.07 & 0.04 & 0.05 & 0.04 & 0.03 & 0.01 & -0.07 \\
\hline Age & $-0.01 *$ & -0.01 & -0.01 & -0.01 & -0.01 & -0.01 & 0.00 \\
\hline Income & -0.02 & -0.02 & -0.02 & -0.01 & -0.01 & -0.01 & -0.01 \\
\hline Female & $-0.26^{*}$ & $-0.23 *$ & $-0.23 *$ & $-0.22 *$ & $-0.21 *$ & $-0.21 *$ & $-0.17^{*}$ \\
\hline $\begin{array}{l}\text { Consider self a member } \\
\text { of an organized } \\
\text { religion }\end{array}$ & & 0.06 & 0.05 & 0.04 & 0.02 & 0.01 & -0.13 \\
\hline $\begin{array}{l}\text { Frequency of } \\
\text { attendance at religious } \\
\text { services }\end{array}$ & & 0.06 & 0.06 & 0.07 & 0.09 & 0.10 & 0.07 \\
\hline Importance of religion & & 0.07 & 0.07 & 0.05 & 0.04 & 0.04 & $0.14^{*}$ \\
\hline $\begin{array}{l}\text { Perception of maternal } \\
\text { figure }\end{array}$ & & & -0.04 & -0.01 & 0.01 & 0.01 & 0.04 \\
\hline $\begin{array}{l}\text { Perception of paternal } \\
\text { figure }\end{array}$ & & & -0.01 & 0.01 & 0.02 & 0.03 & 0.03 \\
\hline
\end{tabular}

\begin{tabular}{|c|c|c|c|c|c|c|c|}
\hline $\begin{array}{l}\text { Adverse childhood } \\
\text { experiences }\end{array}$ & & & & $0.04 *$ & $0.05^{*}$ & $0.05^{*}$ & 0.00 \\
\hline Resilience & & & & & $-0.15^{*}$ & $-0.14 *$ & 0.02 \\
\hline ACEs $\times$ Resilience & & & & & & 0.04 & 0.02 \\
\hline Parental Stress & & & & & & & $0.75^{* * *}$ \\
\hline $\mathrm{R}^{2}$ & 0.05 & 0.08 & 0.09 & 0.10 & 0.12 & 0.13 & 0.48 \\
\hline $\mathrm{F}$ & $3.13 *$ & $3.31 * *$ & $2.73 * *$ & $2.90 * *$ & $3.09 * * *$ & $3.03 * * *$ & $17.88 * * *$ \\
\hline$\Delta \mathrm{R}^{2}$ & & 0.04 & 0.01 & 0.01 & 0.02 & 0.01 & 0.35 \\
\hline$F$ & & $3.44 *$ & 0.74 & $4.10^{*}$ & $4.57^{*}$ & 2.23 & $171.51^{* * * *}$ \\
\hline
\end{tabular}


Table 5. This table depicts the relationship between various predictors and corporal punishment within a nested hierarchical regression.

Corporal Punishment

\begin{tabular}{|c|c|c|c|c|c|c|c|}
\hline & Stage 1 & Stage 2 & Stage 3 & Stage 4 & Stage 5 & Stage 6 & Stage 7 \\
\hline Married & 0.20 & 0.18 & 0.21 & 0.20 & 0.19 & 0.15 & 0.04 \\
\hline Age & $-0.03 * * *$ & $-0.02 * * *$ & $-0.03 * * *$ & $-0.02 * * *$ & $-0.02 * * *$ & $-0.02 * * *$ & $-0.01 *$ \\
\hline Income & -0.02 & -0.02 & -0.01 & -0.00 & $-6.18 \mathrm{e}-4$ & 0.00 & $-3.30 \mathrm{e}-4$ \\
\hline Female & $-0.26^{*}$ & -0.22 & -0.21 & -0.20 & -0.20 & -0.19 & -0.14 \\
\hline $\begin{array}{l}\text { Consider self a member } \\
\text { of an organized religion }\end{array}$ & & 0.17 & 0.12 & 0.11 & 0.20 & 0.07 & -0.11 \\
\hline $\begin{array}{l}\text { Frequency of attendance } \\
\text { at religious services }\end{array}$ & & 0.07 & 0.08 & 0.09 & 0.11 & 0.13 & 0.08 \\
\hline Importance of religion & & -0.05 & -0.04 & -0.06 & -0.07 & -0.07 & 0.33 \\
\hline $\begin{array}{l}\text { Perception of maternal } \\
\text { figure }\end{array}$ & & & $-0.13^{* *}$ & $-0.09^{*}$ & -0.08 & -0.07 & -0.04 \\
\hline $\begin{array}{l}\text { Perception of paternal } \\
\text { figure }\end{array}$ & & & -0.01 & 0.01 & 0.02 & 0.04 & 0.04 \\
\hline
\end{tabular}

\begin{tabular}{|c|c|c|c|c|c|c|c|}
\hline $\begin{array}{l}\text { Adverse childhood } \\
\text { experiences }\end{array}$ & & & & $0.06^{*}$ & $0.06^{*}$ & $0.07 * *$ & 0.01 \\
\hline Resilience & & & & & -0.12 & -0.20 & 0.11 \\
\hline ACEs x Resilience & & & & & & $0.08 * *$ & $0.05^{*}$ \\
\hline Parental Stress & & & & & & & $0.93^{* * *}$ \\
\hline $\mathrm{R}^{2}$ & 0.08 & 0.09 & 0.13 & 0.15 & 0.16 & 0.18 & 0.59 \\
\hline $\mathrm{F}$ & $5.61 * * *$ & $3.74 * * *$ & $4.31 * * *$ & $4.49 * * *$ & $4.28 * * *$ & $4.60 * * *$ & $27.23 * * *$ \\
\hline$\Delta \mathrm{R}^{2}$ & & 0.01 & 0.04 & 0.02 & 0.01 & 0.02 & 0.41 \\
\hline $\mathrm{F}$ & & 1.24 & $5.82 * *$ & $5.37^{*}$ & 2.08 & $7.01 * *$ & $245.15^{* * *}$ \\
\hline
\end{tabular}

$* p<.05 ; * * p<.01 ; * * * p<.001$ 
Figure 1. Interaction between total number of ACEs (ACETOT) and resilience (CDRRISCTOT) on the use of corporal punishment (APQ_CORPUN). Numbers refer to scale scores.

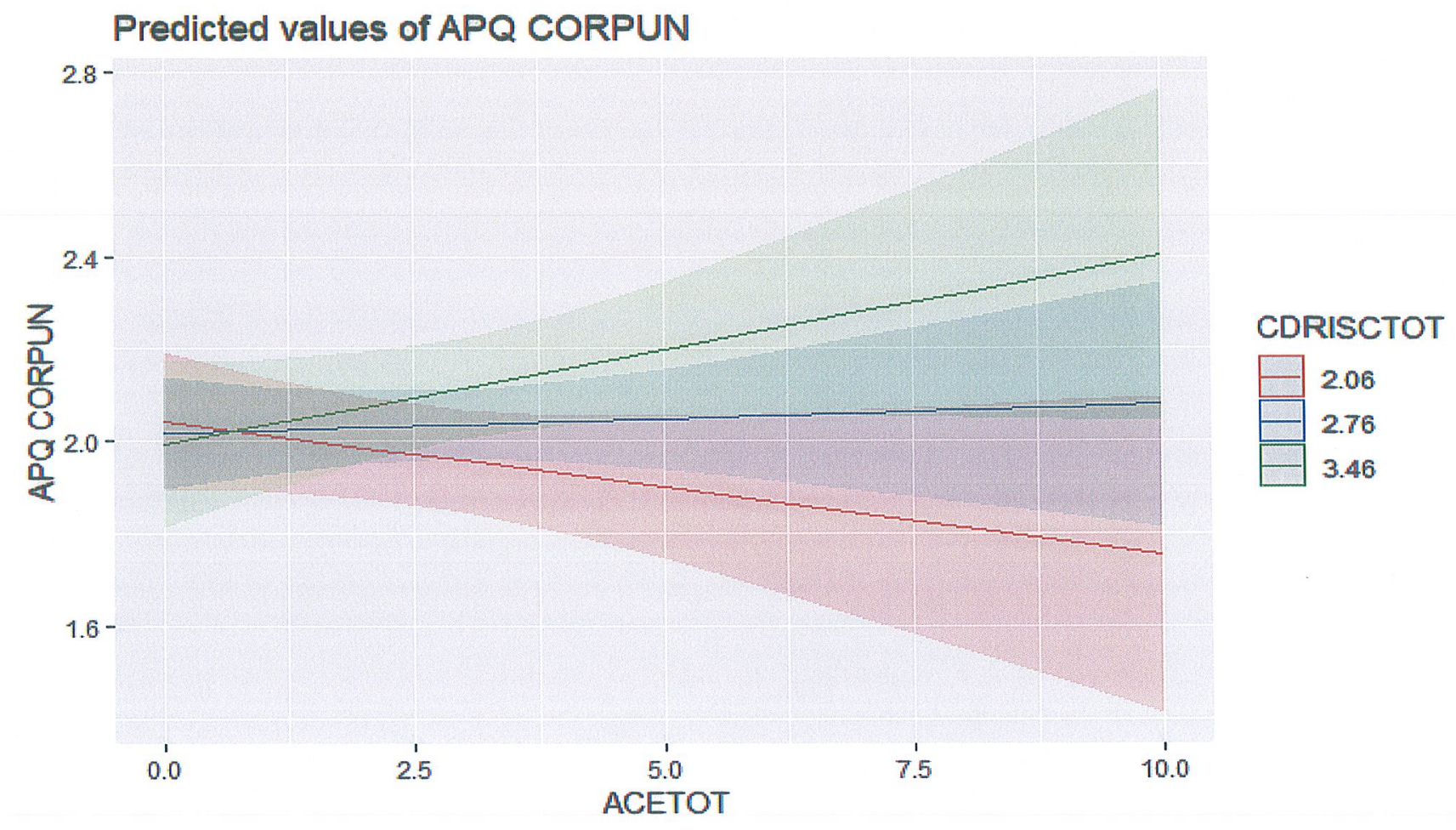

